\title{
Study on Pricing Model of Agricultural Products based on Option Contracts in the Perspective of Farmer-Supermarket Direct Purchase
}

\author{
Xin Congcong \\ School of Traffic and Transportation \\ Lanzhou JiaoTong University \\ Lanzhou, Gansu,China \\ 499263970@qq.com
}

\author{
Yang Xiangfei \\ School of Traffic and Transportation \\ Lanzhou JiaoTong University \\ Lanzhou, Gansu,China \\ 525586420@qq.com
}

\author{
Li Mengna \\ School of Traffic and Transportation \\ Lanzhou JiaoTong University \\ Lanzhou, Gansu,China
}

\begin{abstract}
To avoid the "farmers + supermarket" secondary agricultural supply system due to the risk brought by the market price fluctuations, introducing the option contracts and applying binomial option pricing model in the course of agricultural products pricing, building the pricing model of agricultural production cooperatives and supermarket under the condition of expected profit maximization. Finally, according to the numerical calculation, the rationality of the model was verified and decision-making advice was given. The results we obtained demonstrate that the optimal option order quantity was a strictly monotone decreasing function of the exercise price and the option price, and the agricultural production cooperatives should pay attention to the determination of the exercise price, exercise price was simultaneously correlated with the spot market price, the long-term preparation cost and the short-term production cost.
\end{abstract}

Keywords-farmer-supermarket direct supply; agricultural supply chain; option pricing; binomial option pricing model

\section{INTRODUCTION}

The inherent criticism of traditional circulation model of agricultural products is discussed in the previous papers, which mainly lies in three aspects: asymmetric information, the irrational distribution of profit, uneven share of risk. Accordingly, the "farmer-supermarket direct supply" model arise when :

- The scale and status of supermarket chains in our country is growing rapidly,

- Customers shift their demand for agricultural products, for example, the demand for safe and high quality agricultural products is rising,
- The emergence and development of professional agricultural production organization, which makes the agriculture industrialize [1].

"Farmer-supermarket direct supply" is an agreement or contract based on written documents between the agribusiness (consisted of many scattered farmers) and the firms (i.e., the retail chains), where the farmer produces the fresh agro-food and the firms is committed to buying them under the stipulated conditions regarding products, quantity, price and quality. This innovational circulation model is a contract transaction in essential. "Through contractual arrangements, agro-industry can assist smallholders to shift from the subsistence or traditional agriculture to the production of export-orientated, high-value products [2]". The contract or arrangement, as leverage, distributes timely the profit and corresponding risk between the farmers and the firms.

There are a number of types of models of "farmsupermarket direct supply" which depends on the relationship or connection between the participants. It can be classified into vertical integration and independent contract, where the independent contract includes the fixed quantity contract, price fixed contract and option-based contract [3]. Literature [2] focuses on the contract farming that is subdivide into procurement contract, production management contracts and resource providing contracts. At presents, there have the following mature models of "farmer-supermarket direct supply" in our country:

- Direct purchasing model represented by Carrefour, they purchase agricultural products from the farmers or the agricultural production cooperatives, in addition, 
the agricultural production technology supported by them,

- Distribution first model represented by Wal-Mart, and

- Establishing self-developed brand represented by Tesco, where the supermarket participates in the agricultural production process. In conclusion, there are some overlaps but not mutually exclusive in the aforementioned categories, and among that, the new agro-industrial model of "supermarket + agricultural products processing enterprise + farmers" is the most common. In this model, the supermarket and the professional production cooperative are the two important implement parts.

In summary, "Farmer-Market direct supply", as another innovation in the circulation of agricultural products, greatly reduces the cost of circulation. However, due to the particularity of agricultural products and the complexity of the market, agricultural supply chain becomes vulnerable. Holder is entitled to exercise the option at a given price and a given time; the option price changes along with changes of the underlying assets prices, and the underlying assets prices changes with changes of the market price, which makes it possible to avoid efficiently detrimental effect caused by the change of the market price. Hence, option pricing is of high importance in agricultural supply chain based on option contracts.

\section{LITERATURE REVIEWS}

The existing literature about option is composed of two aspects: the option pricing theory and the option contracts. In the study of option pricing, Fischer Black and Myron Scholes [4] put forward the path-breaking "Black-Scholes" option pricing formula, which resolved option pricing and hedging of the European option in continuous-time. Subsequently, the conclusion of Black\&Scholes was extended to the problem of American option pricing by Merton. Unfortunately, the mathematical tools employed in the Black-Scholes and Merton are quite difficult to understand. Cox-Ross, and Rubinstein [5] presented a simple discrete-time binomial option pricing formula by arbitrage methods, and it was shown be extended to polynomial continuous-time by the means of simplifying the mathematical reasoning process. Thereafter, those methods were improved by many scholars. Simulated annealing method was designed to resolve option pricing problem [6]. Longstaff and Schwartz [7] used the least-squares Monte Carlo (LSM) method to settle the problem of the pathdependent of American option. Similar measures about American option pricing under the stochastic interest rate had been noted [8].For the research on option contracts, BarnesSchuster [9] firstly applied option contracts to the two-stage supply chain with correlated demands, and they found that option contracts responded to the market changes flexibly and improved the performance of total supply chain. It is proved that a mathematics model of upstream supplier's production capacity based on option mechanism realized the overall coordination of the supply chain. In this way, a supply chain coordination model based on option contracts had been established, where the profit of the supply chain members outperforms the profit of the news-vendor models.

Early researches focused primarily on option mechanism of the commercial supply chain. However, little is known about the issue of option pricing in the agricultural supply chain.It is examined that the stochastic behavior of agricultural option price and indicated that the seasonal fluctuation of agricultural products was inconsistent with the assumption of the Black-Scholes option pricing model, but based on constant variance. Someone who combined the game theory and option contracts to manage the circulation loss risk in agricultural product supply chain, whereas resolved the optimal option price under the supply chain coordination. SUN[10] constructed option pricing model based on the maximum profit of the agricultural supply chain under random demand.

Although the results of these existing studies contributed to the literature in some ways, early researches had concentrated on the assumption that the option price and exercise price are exogenous variables and there are few relations between them and the fluctuation of underlying asset price. Indeed, in practice, the market price of agricultural products has some impact on the option price and the exercise price in the agricultural supply chain based on option contracts Therefore, on the basis of previous studies, according to the characteristics of agricultural products, introducing the concept of option into the agricultural supply chain, this paper makes recommendations for the option price's maker and owner in order to achieve win-win situation.

\section{MODEL FORMULATION}

\section{A. The Concept of Agricultural Option}

The agricultural supply chain based on option contracts refers to the supply chain contracts that the agricultural products are defined as the underlying assert in the circulation market, where the option maker is the agricultural cooperatives and the option holder is the supermarket. In this paper, European call option is assumed to be exercised only on the expiration date of the contracts: If the exercise price is lower than the market price on the expiration date, the supermarket will exercise the option; if not, the supermarket will purchase from the spot market instead of exercising the option. This options that is a right instead of an obligation make supermarket avoid the risk caused by fluctuation of agricultural price, while for the agricultural cooperatives, the unused agricultural products are sold on the spot market, and the option cost charged in advance transfers the partial risk to the supermarket, realizing the risk aversion.

\section{B. Problem Description}

Agricultural option is designed to cut the loss of the cooperatives and the supermarket, and the loss is caused by the agricultural market price volatility. First, the following some issues should be settled in the course of introducing option contracts:

- How much is the option cost available? Option price is too high to make the supermarket give up the option, 
and then the cooperatives could lose an opportunity of large orders; option price is too low, the loss of exercising option cannot be satisfied.

- How much is the exercise price? The higher exercise price hinders the supermarket from exercising option at the expiration date.

- For the supermarket, how many options to order in advance are appropriate?

\section{Assumption and Definition}

At the beginning of the period, the supermarket was unaware of the spot market price, but the distribution of price was known. Suppose the spot market price was one of two cases, where the one case was increased price with a certain proportion and the other one was decreased price with a certain proportion. The rate of return on the agricultural products over each period could have two possible values: $u$ $(u>1)$ with probability $p$,or $d(d<1)$ with probability ${ }^{1-p}$.Thus, when the current agricultural products price was $s_{0}$ at $t=0$, the agricultural products price at $t=T$ would be $u s_{0}$ or $d s_{0}$.

This paper also assumes that the interest rate is constant. Let $r_{f}$ denotes the risk-free rate over each period, also $r=1+r_{f}$, due to the non-arbitrage principle, there be $u>r=1+r_{f}>d . c_{0}$ is termed option price of unit agricultural products, $c_{e}$ is termed exercise price of unit agricultural products, $c_{u}$ is the option value at the expiration date if the agricultural products price goes to $u s_{0}, c_{d}$ is the option value at the expiration date if the agricultural products price goes to $d s_{0}$.Option value is affected by the spot market price and the exercise price, hence, at the end of the period, for the call option, we know that $c_{u}=\max \left[u s_{0}-c_{e}, 0\right]$ and $c_{d}=\max \left[d s_{0}-c_{e}, 0\right]$.

\section{Model Foundation}

1) One step binomial option pricing model.

The binomial option pricing model had been firstly presented by Cox-Ross and Rubinstein in their coauthor paper by the arbitrage pricing methods. They employed the portfolio of underlying asset and currency duplicate the option value by assuming no arbitrage and then one step binomial option pricing formula was obtained:

$$
c_{0}=e^{-r T}\left[p c_{u}+(1-p) c_{d}\right]
$$

Where $p\left(p=\frac{e^{r T}-d}{u-d}\right]$ denoted risk neutral probability, because of $d<e^{-r T}<u<1$, so there be $0<p<1$.In addition, Cox-Ross and Rubinstein defined the parameters, $u=e^{\sigma \sqrt{T}}, d=\frac{1}{u}, \sigma$ is termed price fluctuation of unit agricultural products.

\section{2) Multi-step binomial option pricing model}

In the one step binomial option pricing model, underlying asset and the option price after a time step of evolution, which can be accepted by the short-term agricultural option. However, it is possible that the interval time is too long to produce large errors in the computation. In practice, the production preparation period is long, respectively the expiration date of option contracts is late, and the demand of option maker and holder of option contracts cannot be met. Therefore, shorten the time step contributes to improve accuracy of computation by increasing the discrete point of time between contracts time. The interval time is $T$ divided into $n(n \geq 3)$ equal time steps, and then each time step is $\Delta t=\frac{T}{n}$. Among that, $T$ is termed time length measured by years. Under the assumption of no arbitrage, call option value of agricultural products at the expiration date:

$$
c_{n-i, i}=\max \left(u^{n-i} d^{i} s_{0}-c_{e}, 0\right), i=0,1,2, \cdots, n
$$

Similar to one step binomial option pricing model, from back to front calculating multi step binomial option value, these option are discounted at the expiration date. The multi step binomial option price is

$$
c_{0}=e^{-r \Delta t} \sum_{i=0}^{n} C_{n}^{i} p^{n-i}(1-p)^{i} c_{n-i, i}
$$

3) The binomial option pricing model of agricultural products.

Nowadays, we develop agricultural option pricing model on the basis of the binomial option pricing model, there are some hypotheses follows:

- Exercise price is the exogenous variable, and the option price is a variable affected by exercise price

- The spot market is the non-arbitrage and complete market, whereas the information is symmetric in the option contracts.

- At any moments, the agricultural products price exits only two values: either the increasing price or the decreasing price.

The sequence of the transaction of agricultural supply chain based on option contracts is:

- The agricultural cooperatives drafted option price $\left(c_{0}, c_{e}\right)$ before the transaction.

- Sequentially, the supermarket determined the optimal option order $Q$ according to the market demand and the option price made by the cooperatives, and then it paid option cost $Q c_{0}$.Among that, the market demand $D$ is continuous random variable, whose cumulative 
distribution function is $F(x)$, probability density function is $f(x)$, the mean value is $\mu$.

- At the expiration date, the supermarket determined if it exercised the option or not by comparing the agricultural products price on the spot market and the exercise price.

- The cooperatives shall pay for the long-term preparation $\operatorname{cost} b_{0}$, the short-term production $\cos t b_{1}$, and the fixed production cost $K C$.

Thereafter, the determination of exercise price of the cooperatives and optimal option order of the supermarket are discussed under two conditions.

a) Case 1: when $t=T$, if the agricultural products price $d s_{0}\left(d s_{0}<c_{e}\right)$ at the spot market.

At this moment $t=T$, the supermarket will give up exercising option instead of sourcing from the spot market. The expected profit function of the cooperatives and the supermarket are:

$$
\begin{aligned}
& E\left[\Pi R_{1}\right]=\left(s_{0}-d s_{0}\right) \mu-Q c_{0} \\
& E\left[\Pi S_{1}\right]=\left(d s_{0}-b_{1}\right) \mu-K C
\end{aligned}
$$

b) Case 2: when $t=T$, if the agricultural products price $u s_{0}\left(u s_{0}>c_{e}\right)$ at the spot market.

At this moment, the supermarket will attempt to exercise option to reduce the procurement cost. If option order quantities at are greater than actual market demand at, exercising part of option can meet market demand, otherwise, exercising all the option and sourcing from the spot market to meet the market demand. So the expected profit function of the cooperatives and the supermarket are:

$$
\begin{gathered}
E\left[\Pi R_{2}\right]=\left(s_{0}-c_{e}+u s_{0}\right) Q \\
-\left(s_{0}-c_{e}+u s_{0}\right) \int_{0}^{Q} F(x) d(x)-\mu u s_{0}-Q c_{0} \\
E\left[\Pi S_{2}\right]=\left(-c_{0}+c_{e}+b_{1}-b_{0}-u s_{0}\right) Q \\
-\left(c_{e}+b_{1}-b_{0}-u s_{0}\right) \int_{0}^{Q} F(x) d(x)-K C
\end{gathered}
$$

Combining the above two cases, the expected profit of the supermarket is:

$$
E[\Pi R]=-\left\{-c_{0}+\left(s_{0}-c_{e}-u s_{0}\right)[1-F(Q)]\right\}(1-p)
$$

And then the optimal option order quantity of the supermarket is:

$$
Q_{R}^{*}=F^{-1}\left(1-\frac{c_{0}}{u s_{0}-c_{e}}\right)
$$

In the same way, the expected profit of the cooperatives is:

$$
E[\Pi S]=(1-p)\left\{-c_{0}+\left(c_{e}+b_{1}-b_{0}-u s_{0}\right)[1-F(Q)]\right\}
$$

And then the optimal production quantity of the cooperatives is:

$$
Q_{S}{ }^{*}=F^{-1}\left(1-\frac{c_{0}}{c_{e}+b_{1}-u s_{0}-b_{0}}\right)
$$

To realize the coordination of supply chain, the optimal production quantity of the cooperatives shall equal to the optimal order quantity of the supermarket, namely $Q_{S}{ }^{*}=Q_{R}{ }^{*}$, so the optimal exercise price of agricultural products is:

$$
c_{e}=u s_{0}-\frac{b_{1}-b_{0}}{2}
$$

\section{NUMERICAL EXAMPLE}

Suppose the values of the underlying variables are $\quad D \square N\left(100,30^{2}\right), \sigma=0.3, r_{f}=5 \%, T=3, \quad b_{1}=200$, $b_{0}=150$.In this case, .By (12), the optimal exercise price was known with $c_{e}=91$, and by (9), it was can be knew that the optimal option order is $Q_{R}{ }^{*}=102$. Suppose the cooperative has the infinite production capacity to meet all the supermarket demand, also, the cooperatives and the supermarket is rational and risk neutral. The solution procedure of option pricing model as showed in Fig 1.

The paths the agricultural price may follow and their corresponding probabilities (applying the DerivaGem2.01 software) are, when $n=3, s_{0}=100$,

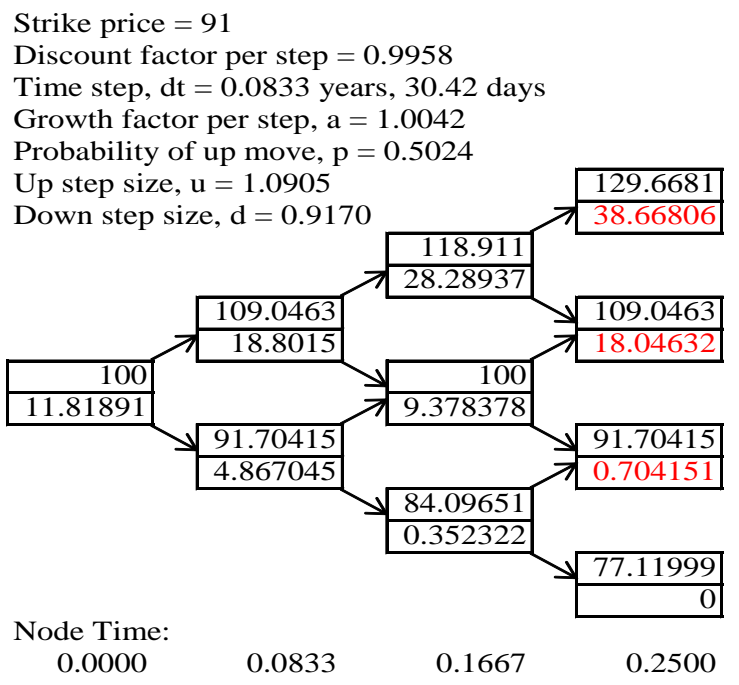

Fig. 1 The solution procedure of option pricing model

It is can be found that the option price is $c_{0}=11.82$. According to the above assumptions, the calculations of the optimal option orders of the supermarket under different pricing strategies as showed in Table 1. 
TABLE I The optimal option orders of the supermarket under different pricing strategies

\begin{tabular}{|c|c|c|c|c|c|}
\hline$c_{e}=91$ & $s_{0}=100$ & $c_{0}=11$. & $s_{0}=100$ & $c_{0}=11.82$ & $c_{e}=91$ \\
\hline$c_{0}$ & $Q_{R}^{*}$ & $c_{e}$ & $Q_{R}{ }^{*}$ & $s_{0}$ & $Q_{R}{ }^{*}$ \\
\hline 10.19 & 107 & 89 & 105 & 96 & 94 \\
\hline 10.59 & 106 & 89.5 & 104 & 97 & 97 \\
\hline 11.00 & 105 & 90 & 104 & 98 & 99 \\
\hline 11.41 & 103 & 90.5 & 103 & 99 & 101 \\
\hline 11.81 & 102 & 91 & 102 & 100 & 102 \\
\hline 12.22 & 101 & 91.5 & 102 & 101 & 104 \\
\hline 12.63 & 100 & 92 & 101 & 102 & 105 \\
\hline 13.03 & 98 & 92.5 & 100 & 103 & 107 \\
\hline 13.44 & 97 & 93 & 99 & 104 & 108 \\
\hline
\end{tabular}

We make sensitivity analysis of different pricing strategies as well as, as shown in the Fig.2:

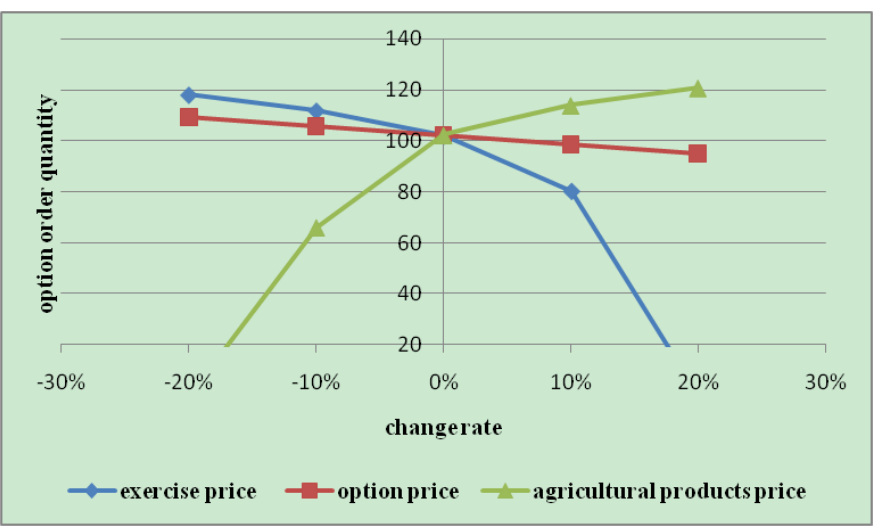

Fig. 2 The sensitivity analysis of the optimal option order quantity

From the TABLE 1, it is knowable that there is a negative correlation between the option order quantity of the supermarket and option price and exercise price, a positive correlation between the option order quantity of the supermarket and agricultural products price. As the Fig.2 shown, comparing with option price, the optimal option order quantity of the supermarket is more sensitive to the exercise price, what's more, when the exercise price rises more than $10 \%$, the optimal option order quantities may decline rapidly. With the rising of unit agricultural products price at the spot market, the supermarket might purchase more option. But, when agricultural products price is down to $15 \%$, the option holder gives up option completely, this is because the option holder exercises option contracts only when the spot market price is greater than the exercise price. If not, the option holder could give up the option contracts.

\section{CONCLUSIONS}

This paper applied the real options theory to agricultural supply chain of "farmer-supermarket direct supply" model, constructed the binomial option pricing model based on a two level supply chain consisted of the cooperatives and the supermarket, resolved the optimal pricing strategy from the perspective of maximum expected profit of them.

Through the sensitive analysis for the optimal option order quantity, it was shown that the optimal option order quantity was a strictly monotone decreasing function of the exercise price and the option price. Besides, comparing with option price, the option holder was more sensitive to exercise price. Hence, the cooperatives pay attention to the determination of the exercise price, exercise price was simultaneously correlated with the spot market price, the long-term preparation cost and the short-term production cost. Though the price volatility in reserve by B-S model was more accurate, the price volatility used in this paper was a historical date.

\section{ACKNOWLEDGMENT}

The authors would like to thank for the project supported by the Provincial Science Foundation for Young Scholars of Gansu Provincial Science and Technology Department (Grant No. 1508RJYA103)

\section{REFERENCES}

[1] Wang C, Chen X. "Option Contracts in Fresh Produce Supply Chain with Circulation Loss," Journal of Industrial Engineering \& Management, vol.6, pp. 104-112, 2013.

[2] N Arumugam, M A Fatimah, E F C Chiew, et al. "Supply chain analysis of fresh fruits and vegetables (FFV): prospects of contract farming," Agricultural Economics, vol.56, pp.435-442, 2010.

[3] Wang Y K, Li W S. "Study of supply chain collaboration pattern on farmer-supermarket direct supply," Journal of Southwest University for Nationalities, 2012.

[4] F Black, M Scholes. "The Pricing of Options and Corporate Liabilities," Journal of Political Economy, vol.81, pp.637-54, 1973.

[5] J C Cox, S A Ross, M Rubinstein, et al. "Option Pricing: A Simplified Approach,” Journal of Financial Economics, vol. 7, pp.229-263, 1979.

[6] HUANG Xiao-yuan. "The Option Pricing Model and Optimal Decision,” Journal of Northeastern University (Natural Science), 1997.

[7] A Francis. Longstaff, S Eduardo. Schwartz. "Valuing American Options by Simulation: A Simple Least-Squares Approach," Review of Financial Studies, vol.14, pp.113-47, 2001.

[8] LIU Jian, MA Chao-qun. "Pricing American Option by LSM Method under Stochastic Interest Rate,” Systems Engineering, 2013.

[9] D Barnes-Schuster, Y Bassok, R Anupindi. " Coordination and Flexibility in Supply Contracts with Options," Manufacturing \& Service Operations Management, vol.4, pp.171-207, 2002.

[10] Sun G H, Lei X U. "Option Contract of Two-echelon Agricultural Supply Chain with Random Supply and Demand," Journal of Industrial Engineering \& Management, 2014. 